\title{
Mathematics and Francoism: the interior exile of the mathematician Ferran Sunyer i Balaguer
}

\author{
Antoni Malet
}

Published online: 3 August 2013

(c) Centro P.RI.ST.EM, Università Commerciale Luigi Bocconi 2013

\begin{abstract}
The article describes the most salient features of Ferran Sunyer i Balaguer's scientific career. Self-taught, despite serious physical disabilities Sunyer reached mathematical maturity in the the two decades following Spain's Civil War (1936-1939), the darkest years of Franco's dictatorship. A distinguished mathematician by international standards, he was never properly recognized as such in Spain. The article places Sunyer's career in the context of the scientific institutions during Francoism, discusses his relationships with great mathematicians such as Jacques Hadamard and Szolem Mandelbrojt, and describes his relative marginalization on the basis of the peculiar values that dominated scientific institutions during the Franco's regime.
\end{abstract}

Keywords Spanish mathematics - Twentiethcentury mathematics - Ferran Sunyer i Balaguer . Francoism - Consejo Superior de Investigaciones Científicas · Jacques Hadamard · Szolem Mandelbrojt

In 1965, at the centre for mathematical research in Oberwolfach, in Germany's Black Forest, thirty European mathematicians met for a week to deal with recent discoveries in the field of harmonic analysis. Only one of them, Ferran Sunyer i Balaguer, had a Spanish passport. This comes as no surprise, considering how little mathematical research of an international level had been developed in Spain since the end of the Spanish Civil War (1936-1939).

The exceptional nature of the presence of Ferran Sunyer was underlined by the serious physical disability that he

\footnotetext{
A. Malet $(\square)$

Departament d'Humanitats, Universitat Pompeu Fabra,

c. Ramon Trias Fargas 25, 08005 Barcelona, Spain

e-mail: antoni.malet@upf.edu
}

suffered, an atrophy of the neuromotor system that confined him to a wheelchair. He could only travel if accompanied by family members, he was unable to write, and he spoke with difficulty.

Here we will discuss some of the most important events of his life, and the role he played in the Spanish and international mathematical communities.

\section{Family and mathematical education}

Ferran Sunyer was born in 1912 in Figueres-the small town where Salvador Dalí was born-, son, grandson and greatgrandson of physicians, in a well-to-do family of landowners. ${ }^{1}$ When his motor disability was discovered, doctors doubted whether or not he would live. Later, even when it became clear that his intellectual abilities were unimpaired, doctors advised against straining his fragile nervous system, and it was believed to be useless to educate him. But by the age of four, he had taught himself to read. From that moment on, his mother did everything possible to provide him the best possible education, but this had to be done at home, since there were no specialized schools available at the time.

The Sunyer i Balaguer family was composed of Ferran Sunyer's mother, Àngela Balaguer (1890-1955) and his three first cousins (two girls and a boy) who were close to Ferran's age, orphans who had been adopted by Mrs Balaguer. His father, Ricard Sunyer (1884-1914), died of tuberculosis when Ferran was 2 years old. The three cousins, Maria, Àngels and Ferran Carbona, were like brother and sisters to him. Physically, Sunyer had to be cared for like a baby. After his mother's death in 1955, his cousins cared for

\footnotetext{
${ }^{1}$ More details about the life of Ferran Sunyer i Balaguer can be found in [3].
} 
him, and they were the ones to conserve his correspondence and papers, today housed at the Universitat Autònoma de Barcelona. They also created the Fundació Ferran Sunyer i Balaguer and the international mathematics prize that commemorate Ferran Sunyer i Balaguer's life and legacy.

When the Sunyer i Balaguer family moved to Barcelona, it is very likely that Ferran Sunyer studied mathematics and experimental science from the notes and textbooks of his cousin Ferran Carbona, who earned a degree in chemical engineering. Sunyer had practically no use of his hands. With time he learned to pick up sheets of paper that he could move on the desk. On a normal working day, in the morning he was left in his room with his books open and the articles laid out that he wished to read. He worked mentally. Occasionally, when he wanted to remember a formula or a partial result, he dictated it. While his mother was alive, she, who knew absolutely nothing about mathematics, would carefully copy those formulas in a notebook; after her death, his cousins continued the practice. That notebook full of formulas was the only tool Sunyer used in his work. When he had an article ready, 'finished in his head', he dictated the text, inserting in it formulas from the notebook.

Everyone who knew the Sunyer i Balaguer family stressed the special nature and human warmth of their home. In Sunyer's adult years, on Saturday afternoon friends and acquaintances gathered together in an environment that some of those who had been there compared to an enlightened salon (Fig. 1).

In 1934 Sunyer wrote his first mathematical paper. While reading one of the foundational works of nineteenthcentury algebra, J. S. Serret's Cours d'Algèbre Supérieure, he had detected an error. An extremely careful reader, in the course of his life Sunyer discovered several errors in writings of other mathematicians, which served him to obtain new results. He sent his paper about Serret's error to the permanent General Secretary of the Académie des Sciences in Paris, the mathematician Émile Picard. He had had no contact with academies and universities, and probably did not know that Serret's work (originally published in 1849), was no longer relevant, and that it was unlikely that Picard, by then an elderly man in possession of many honours and awards, would take the paper into consideration. In fact, Sunyer never received an answer.

Instead, his second attempt, 4 years later, was successful, even in a context that was strongly not in his favour. In December 1938, with Francoist troops at the gates of Barcelona, he sent two notes to one of the greatest mathematicians of the first two decades of the twentieth century, Jacques Hadamard. Sunyer's letter of presentation (in French) asked for Hadamard's opinion on two papers he had written in hopes that the notes would be deemed good enough to be communicated to the Académie des Sciences (which was equivalent to their being published in the

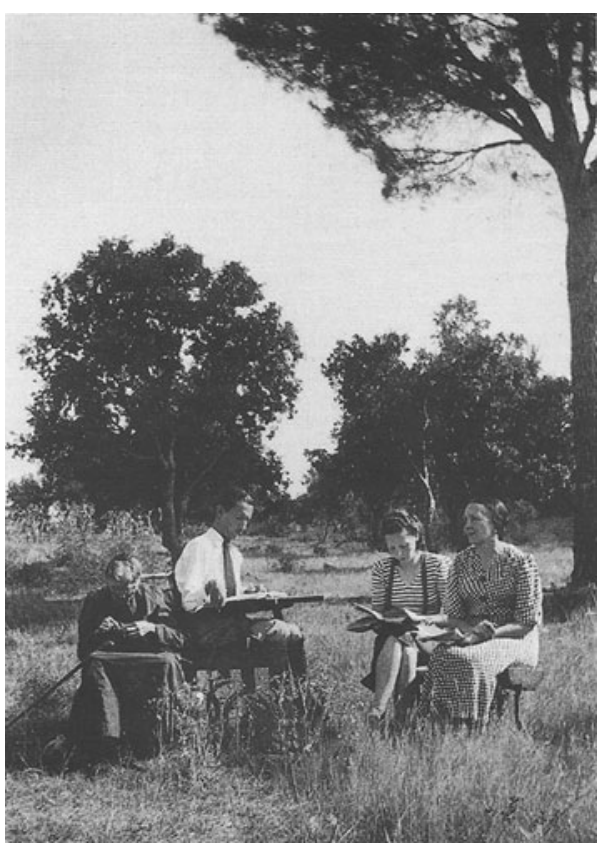

Fig. 1 In Vilajoan, early 1940s. From left to right Modesta Masdevall (Ferran Sunyer's grandmother), Ferran Sunyer, Maria Carbona, Àngels Balaguer. Photo reproduced by generous permission of the Fundació Ferran Sunyer i Balanguer

Comptes rendus of the Academy). Sunyer apologised for any bibliographical omission on account of the civil war:

\section{Monsieur Ja[c]ques Hadamard \\ Paris}

Monsieur: Je vous envoi ci-joint deux notes originales, si vous les jugez suffisantement interessantes je vous prie d'avoir la bonte de le communiquer a l'Academi des Sciences.

En tout cas, je vous serait infiniment reconnaissant d'avoir l'extreme amabilite de me faire connaitre votre autorise et toujours utile opinion qui en raison de ma formation tout-a-fait autodidactique serait pour moi encore d'une plus grande utilite.

La guerre d'invasion qui souffrent les peuples Iberiques ne m'a pas permis de consulter tous les ouvrages et memoires que j'aurais desire. Excusez-moi donc Monsieur si vous trouvez dans cettes notes quelque faute de documentation.

Avec tous mes remerciements anticipées veuillez agreer Monsieur l'assurance de me consideration la plus distingues a la par qu'admirative.

Barcelone 13 dbre. $1938^{2}$

\footnotetext{
${ }^{2}$ We have preserved the French mispellings in Sunyer's original letter. This and other original documents quoted here are available in the Archive "Ferran Sunyer i Balaguer, correspondència" on the Dipòsit Digital de Documents of the Universitat Autònoma de Barcelona, ddd.uab.cat.
} 
(Sir: I send you herewith two original notes, if you think them sufficiently interesting please have the kindness to communicate them to the Academy of Sciences.

In any case, I would be infinitely grateful to have the extreme kindness of your allowing me to know your authoritative and always useful opinion, which, because my training is due completely to self-study, would be of even greater utility for me.

The war of invasion that the Iberian people are suffering has not allowed me to see all the works and memoirs that I would desire. Thus excuse me, Sir, if you find any fault in the documentation in these notes.

With all my anticipated thanks, I send you, Sir, assurance of my most distinguished consideration and admiration.)

Hadamard sent one of the notes to the Comptes rendus and encouraged Sunyer to devote himself to mathematics. This was an enormous recognition, given the prestige and influence of Hadamard, full professor at the École Polytechnique and the Collège de France, Great Cross of the Legion of Honour, holder of honorary doctorate degrees from 36 different universities, member of the National Academy of Science in Washington, DC, the Russian Academy of Sciences and Royal Society in London. Because of the chaotic situation in occupied Catalonia (Barcelona fell to Franco's army on 25 January 1939), Sunyer did not receive Hadamard's response. Instead, he received an indirect report on it from his cousin, Ferran Casabona, who had fled to Paris because of his participation in the production of military ammunition for the Republican army. Direct contact with Hadamard resumed in 1946, when the French mathematician returned to Paris from the United States, where he had gone into exile in 1940. Hadamard put Sunyer in touch with Szolem Mandelbrojt (1899-1983), and this was the beginning of Sunyer's full insertion into the international mathematics community, something that only a few Spanish mathematicians of the period managed to achieve. But before we begin to talk about Sunyer in this context, let us first digress a moment to talk about scientific institutions in Francoist Spain.

\section{Early Francoism and the Consejo Superior de Investigaciones Científicas}

The Consejo Superior de Investigaciones Cientificas (CSIC), equivalent to the Italian Centro Nazionale per la Ricerca (CNR) or the French Centre National de la Recherche Scientifique (CNRS), was the institution in charge of all university research in Spain (and of almost all non-university research as well). ${ }^{3}$ The CSIC was the creature of Francoism: created the year the Spanish Civil War ended, it was inspired and run for almost 30 years by two heavyweights of the regime, José Ibáñez Martín (1896-1969) and José María Albareda Herrera (1902-1966) [7].

Up until 1936, Spanish research and scientific policy remained under the authority of the Junta de Ampliación de Estudios (JAE), a government office endowed with quite a high degree of autonomy. From its founding in 1907, it had been presided over and protected by the prestige of Santiago Ramón y Cajal, the only Spaniard ever to be awarded a Nobel Prize in science (physiology and medicine to be precise). Four features characterised the JAE. First, it took a liberal approach to scientific policy: it did not impose any priority among the various fields of research. Second, it favoured pure science over applied science and technology. Third, it was centralist: all the important laboratories and research centres were created in Madrid. Finally, it was to all effects independent from the universities, which were considered antiquated and impossible to reform. The first Franco government, with Pedro Sainz Rodríguez as Minister of Education and Julio Palacios as his right-hand man for scientific institutions, even though wanting to weed out the personnel of the JAE of 'reds', 'republicans' and whoever else was deemed politically unreliable, still did not change the basic structure of the JAE. In the first year of the Franco regime, the scientific institutions maintained (under a new name) the four basic features of the pre-Civil War JAE.

However, Ibáñez Martín and José María Albareda challenged this continuist approach and organised a tenacious and ultimately successful political battle. Albareda, a founding member of Opus Dei, was Secretary General of the CSIC from 1939 to 1966, the year he died from a heart attack; in the final years he was simultaneously the President (rector) of the University of Navarra, owned and run by Opus Dei, ${ }^{4}$ and was the only private university that was authorised to exist under Francosim. Ibáñez was president of the CSIC from 1939 to 1967 . He was the Minister of National Education (1939-1951) and later on, without giving up the CSIC presidency, he was Franco's ambassador to Lisbon from 1958 until his death in 1969. These were the years when Franco negociated with Juan of Bourbon (who resided in Lisbon) the conditions for conferring, at the dictator's death, the crown of Spain to his son Juan Carlos (today Juan Carlos I).

The CSIC inherited all the laboratories, research centres, real estate and other possessions of the JAE, and also won control over other learned institutions that the JAE had

\footnotetext{
${ }^{3}$ For more about the first decades of the CSIC, see [4].

${ }^{4}$ For more about Albareda and the CSIC, see [6].
} 
never controlled. As far as the organising principles were concerned, the CSIC opposed the ways of the JAE described above. As in all totalitarian regimes, the demands of the economic autarchy required development of its own technology, and as a consequence, the CSIC of early Francoism favoured applied science and laboratories for technology. Secondly, it was strongly anti-liberal in political as well as in disciplinary terms. It prioritized fields and lines of research; it supported applicational approaches, but also favoured the humanities and social sciences, whose activities then supported the ideology and propaganda of the new regime. Obviously research groups directed by figures close to the regime easily found favour. In the third place, the CSIC was less centralistic than the JAE. It spread to many provincial towns in Spain to favour the totalitarian and 'national' aims of the new regime. Given that the CSIC was the regime's intellectual arm, it had to be omnipresent in all institutions, in order to represent Francoism and control its territory. Finally, the CSIC funded university research; actually it was the only source of funds for university research up until the mid-1960s. If the CSIC authorised the creation of a research group related to a university chair or group of chairs, the group received funding from the CSIC for books, laboratory materials, overtime salaries, and bonuses for full, assistant and adjunct professors.

Among other things, the CSIC created the figure of the full-time researcher. However, paradoxical as it may seem, even though he was one of Spain's most profound and productive mathematicians, Ferran Sunyer achieved this position only in 1962, after he had overcome absurd obstacles. In the 1940s and 1950s, he won many research awards. Some were from institutions in the provinces (of Barcelona in 1947 and 1948, of Zaragoza in 1950). More important were those conferred on him by the Academia de Ciencias in Madrid (1954) and the three that were assigned to him by the CSIC, in particular the 1956 Premio Nacional de Ciencias "Francisco Franco", which awarded the winner 50,000 pesetas. This was the most important and politically significant prize of Francoism, and was an enormous amount of money for the time. In 1957, he was awarded another prize from the Academia de Ciencias in Madrid.

For Ferran Sunyer, these prizes constituted the means for legitimising himself before the academic community. Because he was an autodidact and worked in isolation from other professional mathematicians, he couldn't count on traditional inroads to the scientific community, such as the protection of scientists who were already 'consecrated' (like thesis advisors), friendships with other members of the community, or teaching collaborations. The university, given his physical limitiations, was off limits for him. For this reason he accumulated the majority of his prizes in the early years, when he needed to make a name for himself in order to obtain a position at the CSIC.

In Barcelona, all chairs of mathematics in the faculty of science comprised a department of the CSIC named Seminario Matemático. ${ }^{5}$ In January 1948 Sunyer officially applied to be named a collaborator of this department. In his curriculum he cited the works he had published up to that time: three notes in the Comptes Rendues de l'Académie des Sciences of Paris, an article in the Revista Matemática Hispano-Americana, the memoire honored with the Agell Prize of the Barcelona Academy, and the one on which he was working following Mandelbrojt's suggestions, eventually published in the prestigious journal Acta Mathematica founded by Gösta Mittag-Leffler. Also part of his presentation was his collaboration with Mandelbrojt. The application was approved by and he was named Profesor-Colaborador Temporal with a token stipend of 5,000 pesetas a year. The stipend was very small, equal to the supplementary grant that full professors received; in comparison, the stipend of a doctoral scholarship was 12,000 pesetas a year. In the years that followed, Sunyer worked to improve his position within the CSIC, but was only relatively successful. His salary was in fact increased, but his attempts to obtain a permanent position as a researcher failed. The reasons for this were never clear. The main argument was based on the fact that he didn't have a doctoral degree. In truth, according to the statutes of the CSIC, the Executive Committee had the power to nominate anyone they wanted to simply on the basis of extraordinary merit.

Julio Rey Pastor (1888-1962) and Ricardo San Juan y Llosá (1908-1969), two influential mathematicians in Franco's Spain, helped Sunyer in his relations with the CSIC. Rey Pastor had been, before the civil war, the Spanish mathematician who enjoyed the greatest international prestige and recognition; he had been a member of the Real Academia de Ciencias in Madrid since 1920, and became a member of the Real Academia de la Lengua Española in 1954. Thanks to the British Astronomical Society, a crater on the Moon is named for him. After the war, the regime wanted to attract him and offered him wellpaid positions in the CSIC, which he accepted-both for the money and with hopes of regaining his former influence within Spanish institutions. San Juan, a disciple of Rey Pastor and also a member of the Real Academia de Ciencias from 1956, was a misanthropic man held in little esteem by students as well as by many colleagues of the University of Madrid. He was, however, an original, highlevel mathematician who for many years carried out research funded by the United States Air Force. Until 1990,

\footnotetext{
5 For more on mathematical research during the Spanish Civil War, see [5].
} 
San Juan and Sunyer were the only Spanish mathematicians to have published in Acta Mathematica.

Sunyer and San Juan met personally on the occasion of a lecture that San Juan was invited to give in Barcelona in 1952. From that time on, San Juan supported Sunyer, in particular when the latter submitted papers to prizes in Zaragoza and Madrid. Between 1953 and 1955, Rey Pastor-on San Juan's recommendation-requested a position for Sunyer in the CSIC, but without success. Finally, after having met Sunyer in person in Barcelona in December 1955, Rey Pastor met with the president of the CSIC, Ibáñez Martín, and convinced him to find a solution to Sunyer's precarious work situation. It was a few months after that that Sunyer won the Premio Nacional de Ciencias 'Francisco Franco', and was at the same time awarded a grant created for him ad hoc, providing him with 60,000 pesetas a year.

For his part, however, Sunyer aspired to a permanent research position in the CSIC at the highest academic level, but he was excluded from the competitions that opened the door to permanent positions because of his lack of a doctorate. At the end of 1956, Sunyer decided to earn his doctorate. He enrolled in an liceo to earn his Bachillerato (the secondary or high school diploma); in 1959 he graduated in Mathematics. However, Spanish regulations did not allow obtaining the doctorate immediately after the first university degree. So it wasn't until 1962 that he applied and won a position of colaborador científico de segunda (second class scientific collaborator), in the CSIC. During all these years the ad hoc scholarship he had been granted in 1956 was maintained. In 1964 he was named colaborador científico de primera (first class scientific collaborator). In November 1967, a month before his death, he was finally promoted to the highest-level position within the CSIC, the investigador cientifico (scientific researcher).

In the 1950s Sunyer collaborated in Barcelona with the mathematician Ernest Corominas (1913-1992), son of an prominent leftist intellectual and Republican politician. Corominas, who had been an officer in the Republican army decorated for merit during the war, went into exile in Argentina in 1939. On the recommendation of Rey Pastor, he obtained a university position there. In 1947 he left Argentina because of Peronist repression and settled in Paris, where he wrote his doctoral dissertation under the supervision of Arnaud Denjoy. In 1952 he returned to Barcelona and, again supported by Rey Pastor, obtained a position in the CSIC. Despite Rey Pastor's efforts, however, Corominas's appointments were always temporary and badly-paid-presumably because of his family and military background. Disappointed by the lack of support, in 1960 Corominas left for Venezuela. In 1964 his French colleagues finally obtained a full professorship for him at the University of Lyon, where he concluded a brilliant mathematical career as a French citizen. In the years that Corominas spent in Barcelona, he and Sunyer were very close both professionally and personally. In spite of the fact that they only published one joint article ([13], the one with the famous theorem on polynomiality, see below), the exchange of mathematical ideas between the two was profound and constant. On 13 September 1960, in a farewell letter before his departure for Venezuela, Corominas wrote:

So we won't see each other again, before my departure. But it seems to me not to matter. Our friendship is deep, by temperament and affinity. It was a paradox that we found each other in such a rarified milieu and become connected scientifically in such a rich way when that is difficult even in contexts of high culture.

\section{Sunyer and the international mathematics community}

The contacts with Szolem Mandelbrojt in the late 1950s served Sunyer for getting to know other French mathematicians, and more in general, to move within international circles. Beginning in the 1950s, Sunyer published works of great importance, as well as more than ten notes that appeared in the Comptes Rendues de l'Académie des Sciences. Particularly important among these are "Values of entire functions represented by gap Dirichlet series", published in 1953 in the Proceedings of the American Mathematical Society, and "Sur la substitution d'une valeur exceptionelle par une proprieté lacunaire" published in 1952 in Acta Mathematica.

Further events testify to the international circulation of these works, and to the growing number of acquaintances that Sunyer made in Europe and the United States. In 1952 he was invited to publish a paper in the Rendiconti del Circolo Matematico di Palermo. In these same years, on the occasion of the celebration of the ninetieth birthday of Hadamard, Henry Corbière (assigned by a French magazine to collect and prepare the papers written in honour of the Franch mathematician) wrote to Sunyer to request a brief contribution. Among others who took part in the initiative were Louis de Broglie, Gaston Julia, Paul Montel, Maurice Fréchet, Paul Lévy and Alexander Ostrowski. Sunyer exchanged extracts and comments on his most recent works with professors from the University of California, Cornell University, North Georgia College and Syracuse University. Mathematical Reviews and the American Mathematical Society requested copies of his works when they were unable to procure them via the usual channels. 
One anecdote from an international congress of mathematicians held in Nice in 1957 is indicative of Sunyer's personality and his growing prestige within the international mathematical community (Fig. 2). For reasons we won't go into here, the Congress had explicit political overtones: it was a French initiative, with the agreement of Italy and Eastern European countries, undertaken to counterpose the expansionism of anglophone culture that followed the second world war [8]. Some 140 mathematicians from fourteen different countries gathered in Nice. The French delegation was quite strong, both quantitatively and qualitatively: fifty-three mathematicians headed by Gustave Choquet, Paul Montel, Gaston Julia, André Lichnerowicz and Henri Cartan. The Italian delegation, with forty-three members, was equally important, while the delegations of the other countries had ten members at most. Sunyer asked Mandelbrojt to introduce him to Waclaw Sierpinski (1882-1969), to whose notice he wanted to bring an error contained in his famous book Hypothèse $d u$ continu, published in 1934. Mandelbrojt strongly doubted that the self-taught Sunyer could correct an error of Sierpinski's, much less one not previously discovered in a very-well known reference book published twenty-three years earlier. With more than 50 years of professional life behind him, more than 600 publications, honorary doctorate degrees from universities in Paris, Amsterdam, Bordeaux and Prague, and membership in the most prestigious academies of Europe, Sierpinski was undoubtedly a great, international mathematical personality. In a series of fundamental contributions from 1915 to 1920, he had proven that the axiom of choice was connected to the theory of real functions created at the beginning of the twentieth century, as well as with Lesbesgue's measure theory. In those same years, Sierpinski had founded a 'Polish School of mathematics' that was above all concerned with problems of foundations, set theory and functional analysis. Mandelbrojt tried to dissuade Sunyer, but in vain. The introduction took place, and as a result of the conversation Sierpinski published a note in which he rectified the error, praising Sunyer's role in identifying it. In apologising for not being able to explain how the error arose, Sierpinski added a few details to explain how the second world war and the Gestapo interfered with the scientific career of Stanislas Saks, who was Sierpinski's collaborator and the author of the theorem that contained the error:

En ce qui concerne la démonstration ultérieur, $M$. Sunyer Balaguer a remarqué qu'elle n'est pas correct ... Stanislas Saks été tué par la Gestapo en novembre de 1942 et ses manuscrits n'existent plus. J'ai perdu moi-meme dans les flammes ma biblioteèque et mes archives en 1944. Il est donc impossible d'établir

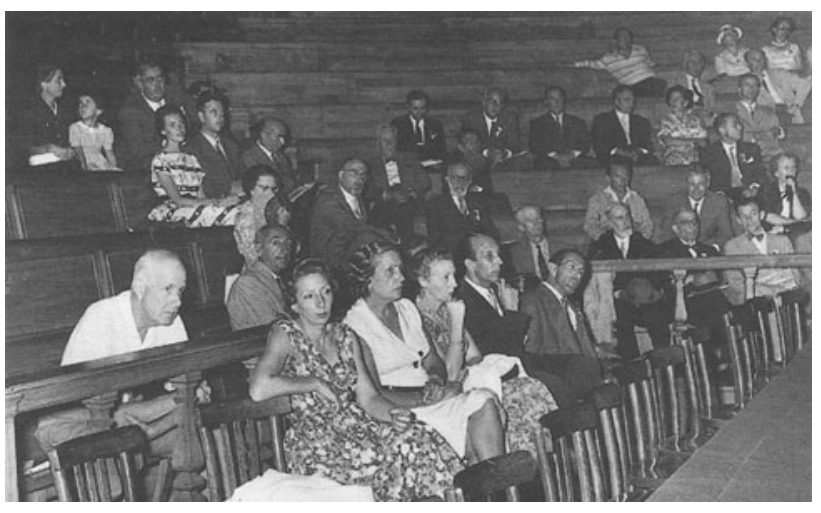

Fig. 2 Nice, 1957. Ferran Sunyer is seated at the far end of the front row. Photo reproduced by generous permission of the Fundació Ferran Sunyer i Balanguer

audourd'hui quelle était la démonstration de S. Saks. En tout cas il est étonnant que grace à M. Sunyer Balaguer, l'on n'ait trouvé la faute, que 23 années après l'apparition de la première édition de mon livre [14, p. 117-118].

(Regarding the following proof, Mr. Sunyer Balaguer has noted that it is not correct... Stanislas Saks was killed by the Gestapo in November 1942 and his manuscripts no longer exist. I myself lost my library and my archives in the flames in 1944. It is therefore impossible to determine today what the proof of $\mathrm{S}$. Saks was. In any case it is remarkable that thanks to Mr. Sunyer Balaguer, the fault has been found 23 years after the appearance of the first edition of my book.)

Sunyer's relationship with Sierpinski did not end here. Starting with the extracts that the Polish mathematicians sent to Barcelona, Sunyer proved a theorem on types of orders that Sierpinski found 'new and interesting', and which he published in the journal he directed. Sunyer and Sierpinski remained in contact more or less regularly at least until 1964. At the end of 1958, on behalf of the CSIC, Sunyer obtained an article by Sierpinski for the journal of the Seminario Matemático.

Between 1956 and 1960, Sunyer also carried on an intense mathematical correspondence with Archibald J. Macintyre (1908-1967), first a senior lecturer at the University of Aberdeen and from 1958 a professor at the University of Cincinnati (USA). In 1959 Macintyre invited Sunyer to visit several American research centres in view of an exchange of researchers between America and the University of Barcelona, a proposal that was later rejected by both the University and by the CSIC. While negotiations were underway, Macintyre was deeply upset by the death of his wife, and the correspondence between the two mathematicians was interrupted. 
One of the most important figures for Sunyer's relationship with the North American mathematical community was Ralph P. Boas Jr. (1912-1992), professor of mathematics at Northwestern University from 1950 and a specialist in topics close to those of Sunyer. For 6 years Boas was the editor-in-chief of Mathematical Reviews and from 1956 to 1961 he was one of the editors of the Proceedings of the American Mathematical Society. Boas was well acquainted with Sunyer's contributions. He had written reviews of a dozen of these for Mathematical Reviews and had peer-reviewed and published his article "On entire functions defined by a Dirichlet series" in the Proceedings. Boas asked Sunyer to act as referee for at least four articles submitted to the Proceedings.

In his famous introduction to real analysis, A Primer of Real Functions [1], Boas particularly underlined the elegance and depth of a theorem by Sunyer and Ernest Corominas. In 1953 Sunyer and Corominas had proven that an infinitely differentiable function of real numbers, such that for each real $x$ there exists at least one derivative of the function that becomes null at point $x$ (the order of the derivative does not necessarily have to be the same for all $x$ 's), is necessarily a polynomial; a sketch of the proof was published in 1954 in the Compte rendus de l'Académie de Sciences. In July 1959 Boas informed Sunyer that he had included the theorem in A Primer of Real Functions, which he was then writing. The book finally appeared in 1960 and became a classic in the field, with a second edition in 1972, a third edition in 1981, and a fourth edition, edited by his son Harold P. Boas, in 1997. In addition to highlighting the theorem of Sunyer and Corominas, Boas used it as a kind of organising principle for the book. In his review of the book in the Bulletin of the American Mathematical Society,

\section{S. Gál recounts that Boas had decided that:}

in order to have a guiding line he planned to include everything which is necessary to formulate and prove the following proposition: Suppose the continuous real valued function $f$ of a real variable $x$ has derivatives of all orders everywhere and for each $x$ there is an order $n(x)$ such that the $n(x)$ th derivative of $f$ vanishes at $x$. Then $f$ is a polynomial function [2, p. 10].

This is, of course, in slightly different words, the theorem of Sunyer and Corominas.

From 1962 until his death, Sunyer carried out research funded by the scientific branch of the United States Navy, the famous Office of Naval Research (ONR). It is likely that the academic and personal letter of recommendation written by Boas in favour of Sunyer was crucial in convincing the authorities of the ONR to approve the research proposed by Sunyer. The ONR funded both projects in research applied to military uses, and projects of pure research. It is certain that two other Spanish mathematicians, Ricardo San Juan and Sixto Ríos, also had contracts with the American military. These contracts stipulated generically the topics which Sunyer was to work on-freely chosen by Sunyer himself-and also permitted him to freely publish the results. He was only required to submit a copy of his work to the ONR, as well as quarterly and annual reports. The contract provided an excellent remuneration, more than 150,000 pesetas a year (about double the stipend of a scientific collaborator of the CSIC). At the 1965 meeting in Oberwolfach mentioned at the beginning of our discussion, Sunyer explained some of the results obtained from the research funded by the Navy, later published in the article 'Approximation of functions by linear combination of exponentials' [10]. Other results of this research were collected in the memoire entitled 'Sobre un espacio de funciones enteras de orden infinito' [11], winner of the Antoni Martí i Franquès Prize in 1966. Finally, other results were published in a posthumous paper published in 1970 in a volume in honour of A. J. Macintyre [12].

In the 1960s, young mathematicians such as Yves Meyer and Henri Mascart began to be helped by Sunyer, receiving critical comments on their work. Mandelbrojt and Jean-Paul Kahane advised other mathematicians working in southern France to contact him, and this was done by Edwin J. Akutowicz and Aimée Baillette, who went several times to see Sunyer in his home in the Sarrià district in Barcelona; Sunyer directed Bailette's research until his death.

The Indians Pawan Kumar Kamthan of Pirlani and Aluru Raghu Rami Reddy of Madras were the young mathematicians who most benefitted from Sunyer's authority and prestige, finding in him a true master and guide in the international community. In 1962 Sunyer received the first of a series of articles by Kamthan, a professor of mathematics at Birla College (today Birla Institute of Technology $\&$ Science in Pilani). After a rigorous critical analysis of the works, Sunyer improved them and published them in Collectanea Mathematica and the Revista Hispano-Americana de Matemáticas. At the beginning of 1962, Kanthem expressed his intention to transfer to Barcelona in order to work with Sunyer, provided that he was able to find financial aid. Sunyer did everything possible to obtain a scholarship for him, either through the university or the CSIC, as well as the Fundación Juan March and other cultural institutions, but without success: the dreadful Francoist bureaucracy took 2 years (!) before pronouncing a definitive no. In the end Kamthan, thanks to a letter of recommendation from Sunyer, was able to obtain a postdoctoral scholarship from the National Research Council of Canada. In April 1965, Aluru Raghu Rami Reddy, a student at the Ramanujan Institute of Mathematics of the University of Madras began a correspondence with Sunyer, sending him an article for Revista Matemática Hispanoamericana. A few months later the University of Madras 
asked Sunyer to act as chief examiner of Reddy's doctoral dissertation, and he accepted. Sunyer improved some of Reddy's works published in Collectanea Mathematica and in the Revista Matemática Hispano-americana. As in the case of Kamthan, Sunyer wrote a letter of recommendation for Reddy when he applied for a position as professor at the universities of Manitoba and Calgary (both in Canada). Reddy also wanted to work in Barcelona with Sunyer, but it wasn't possible to find funding for him either.

\section{Sunyer and the Spanish mathematical community}

The quality of Sunyer's contributions and his presence in the international community rendered him unique among Spanish mathematicians of his day. The volumes of the Mathematical Reviews make it possible to quantify Sunyer's contributions in the Spanish context. A comparison with the thirty-seven most important Spanish mathematicians of the time places Sunyer well above average in terms of both the absolute number of his publications as well as the number of them published in international journals. With forty-one works in all and seventeen in French and English, he is one of the five most productive Spanish mathematicians, and one of the four who most published internationally.

In spite of all this, Sunyer received scant official recognition on the part of his Spanish colleagues. While it is true that he received the Franco Prize, this was due to a decision made by the President of the CSIC in an extraordinary move. The difficulties and delays in appointing him to a research position were irritations and humiliations that Sunyer simply had to endure. He had no doctoral students, nor was he even part of a doctoral thesis commission ('tribunal', as it was called at the time). On the occasions of the congresses or annual meetings of the Sociedad Matemática Española, homage was paid to the mathematicians considered to be important by, for example, asking them to present a plenary lecture, or other similar gestures of public recognition. Sunyer never received this kind of invitation.

Sunyer was invited numerous times to collaborate with the two principal Spanish mathematical journals, the Collectanea Mathematica and the Revista Matemática Hispano-Americana. He always accepted these invitations, either publishing his own articles or soliciting papers from his colleagues in other countries. Nevertheless, he was never given any power within these journals. Sunyer kept one specific letter, dated 22 December 1966, which he found both amusing and offensive. It came from Francisco Botella Raduán, president of the Real Sociedad Matemática Española, which published the Revista Matemática Hispano-Americana. The letter included a bank check for 3,000 pesetas and said:

Muchas veces le hemos molestado solicitando su colaboración ... Por ello, repetidamente se ha propuesto en las reuniones de la Junta Directiva expresarle la mas sincera gratitud por el calor con que ha respondido Vd. siempre a nuestros ruegos. $Y$ siendo criterio de la Sociedad corresponder siquiera de un modo simbólico, dada la modestia de nuestros medios, a estos trabajos extraordinarios, le ruego acepte esta pequeña muestra de nuestro afecto ... (Many times we have disturbed you soliciting your collaboration ... For this, it has been repeatedly proposed in the sessions of the Board of Directors to express our most sincere gratitude for the warmth with which you have always responded to our requests. And it being the policy of the Society to recognise, albeit in a symbolic way given the modesty of our means, these extra works, I pray you to accept this small demonstration of our esteem....)

The recognition for intellectual collaboration thus arrived in the form of a small monetary compensation at Christmas time - a kind of tip - like the kind given to an efficient employee. One possible explanation is that Botella Raduán was knowingly excluding Sunyer from the powerful inner circle of the Real Sociedad Española and its Revista. Along with the 'tip', Botella was sending a message that Sunyer was not one of them, and that his contribution was being paid for because he was a 'third party'. Or-and we hardly know which alternative is worst - the board of directors of the Sociedad and the editorial board of the Revista perhaps did not know that the proper way to reward the merits and work of a scientist is to give him a position of power within the scientific community, not a Christmas tip.

For scientists, recognition from their colleagues is a prime motivation. Michael Polanyi, Robert Merton and many others have underlined the fact that, in scientific communities that are highly productive and creative, scientific value correlates with the community's institutional structure, in the sense that influence and power accompany quantity and quality of production: 'When [science as] institution operates effectively, the augmenting of knowledge and the augmenting of personal fame go hand in hand' [9, p. 323].

The increase of prestige is rewarded with power within the scientific community: power to assign positions, orient publications, etc. It is here that Sunyer's marginalization from the Spanish mathematical community-so well illustrated by the Christmas 'tip' offered to him — goes beyond being just an anecdote and shows a basic deficiency of the Spanish scientific community. Sunyer was undoubtedly a leader of Spanish mathematics from the point of view of research, and yet he always found himself hierarchically below professors with less academic merit who never gave him the scientific recognition that he merited.

Sunyer's academic alienation was due, first of all, to his physical condition, at a time when physically disabled 
people were not even granted the right of becoming fully integrated participants in social life. The Institut d'Estudis Catalans itself rejected the idea of his becoming a member, because of his disability. This was explained to him in person, with the conviction that he would understand and agree! Another factor that underlay his marginalization was his being an autodidact and outsider with respect to the groups and the 'schools' that dominated Spanish mathematics. Finally, it is quite plausible that he paid a price for never renouncing his Catalan culture. From the efforts he made to maintain the Catalan spelling of his surnames to the publications in the Catalan language during the 1940s and $1950 \mathrm{~s}$, when doing that had enormous political significance, from his contributions to Catalan mathematical terminology, up to is participation in the semi-clandestine institutional life of the Societat Catalana de Ciències, Sunyer never made a secret of his identity. All of this may have had a negative influence on his status within the Spanish mathematical community.

For his dedication to research, his publications, his international contacts and his untiring activity, Sunyer represents an alternative model to that of the typical university professor in the time of Franco. It is here that it is necessary to look for deeper explanations for his forced exile from the milieu of the scientific communities that were nourished and shaped by the Francoist regime.

Translated from the Italian by Kim Williams

\section{Appendix: The Legacy of Ferran Sunyer i Balaguer}

Recently Catalan television has newly recognised the central position of Ferran Sunyer i Balaguer, rendering homage to the mathematician with a creation and broadcast of a documentary about his life. It is available at:

http://www.tv3.cat/videos/4545916/Ferran-Sunyer-i-

Balaguer-Historia-dun-exili-interior.

Of equal significance is the Ferran Sunyer i Balaguer Prize awarded annually by the Fundació Ferran Sunyer i Balaguer to an original, unpublished, monographic work of a mathematical nature of at least 150 pages in length and written in English. The prize, with a prize worth more than $€ 15,000$, includes publication of the monograph by Birkhäuser in the book series "Progress in Mathematics". See http://ffsb.iec.cat/EN/premi.htm.

\section{References}

1. Boas, R.P.: A Primer of Real Functions, Carus Monograph 13. Wiley, New York (1960)

2. Gál, I.S.: Review of a primer of real functions. Bull Am Math Soc 68, 10-12 (1962)
3. Malet, A.: Ferran Sunyer i Balaguer (1912-1967). I.E.C, Barcelona (1995)

4. Malet, A.: El papel político de la Delegación del CSIC en Barcelona (1941-1956). Arbor 160/631-632, 413-439 (1998)

5. Malet, A.: La Guerra Civil i les institucions catalanes de recerca: El cas de la recerca matemàtica (1907-1967). In: Roca A., et al. (eds.) La Ciència en la Història dels Països Catalans, III, 225-267. Univ. de València-IEC, València-Barcelona (2005)

6. Malet, A.: Las primeras décadas del CSIC: Investigación y ciencia para el franquismo. In: Romero, A., Santesmases, M.J. (eds.) Un siglo de política científica en España, pp. 211-256. Fundación BBVA, Madrid (2008)

7. Malet, A.: José María Albareda (1902-1966) and the formation of the Spanish Consejo Superior de Investigaciones Científicas. Ann Sci 66: 307-332 (2009)

8. Malet, A.: Cold War Geopolitics and French Mathematicians: The Groupement des mathématiciens d'expression latine, 1957-1985. In: Tazzioli, R., Mazliak, L. (eds.) Des mathématiciens et des guerres: histoires de confrontations (2013)

9. Merton, R.: The Sociology of Science. University of Chicago Press, Chicago (1973)

10. Sunyer Balaguer, F.: Approximations of functions by linear combinations of exponentials. Collectanea Mathematica 17, 145-177 (1965)

11. Sunyer Balaguer, F.: Sobre un espacio de funciones enteras de orden infinito. Actas de la VI Reunión Anual de Matemáticos Españoles, Sevilla (1966)

12. Sunyer Balaguer, F. On the assymptotic paths of entire functions represented by Dirichlet series. Mathematical Essays Dedicated to A. J. Macintyre, pp 37-41. Ohio University Press, Athens (1970)

13. Sunyer i Balaguer, F., Corominas, E: Condiciones para que una función infinitamente derivable sea un polinomio. Rev. Mat. Hispano Americana 4, 14 (1954)

14. Sierpiński, W. Sur un théorème de S. Saks concernant les suites infimes de fonctions continues, Fundamenta Mathematicae 46, $117-121$ (1958)

\section{Author Biography}

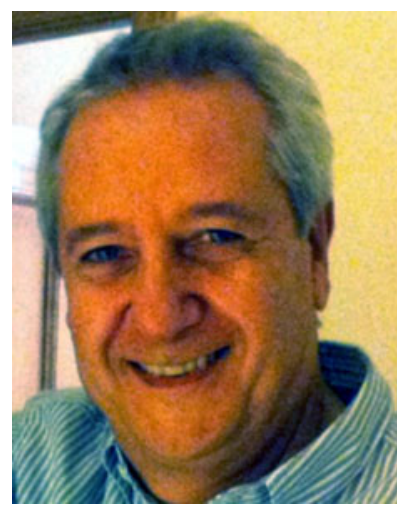

Antoni Malet is Professor of History of Science and Chair of the History of Science Unit in the Universitat Pompeu Fabra (Barcelona). He majored in mathematics in the Universitat de Barcelona and received a doctorate in History from Princeton University (1989). Corresponding member of the Académie International d'Histoire des Sciences (París), his research project 'Tacit Knowledge and Conceptual Change in Early Modern Mathematics', to be developed at the Max-Planck Institute for the History of Science, has been awarded a Marie Curie senior grant from the Gerda Henkel Foundation (2013-2014). He has been visiting research fellow in the universities of Princeton, California (San Diego), Cornell, Toronto, and París VII. He is a member of the editorial board of Annals of Science and Historia Mathematica, where he served as Book Review Editor (2006-2011). He works on early modern mathematics and optics and on Spanish science during the Franco regime. 